\title{
Hepatitis B surface antigen titer is a good indicator of durable viral response after entecavir off-treatment for chronic hepatitis B
}

\author{
Han Ah Lee', Yeon Seok Seo', Seung Woon Park', Sang Jung Park', Tae Hyung Kim', Sang Jun Suh', Young Kul Jung', \\ Ji Hoon Kim', Hyunggin $\mathrm{An}^{2}$, Hyung Joon Yim', Jong Eun Yeon'1, Kwan Soo Byun', and Soon Ho Um \\ Departments of ${ }^{1}$ Internal Medicine and ${ }^{2}$ Biostatistics, Korea University College of Medicine, Seoul, Korea
}

Background/Aims: Clear indicators for stopping antiviral therapy in chronic hepatitis B (CHB) patients are not yet available. Since the level of hepatitis $B$ surface antigen $(\mathrm{HBsAg})$ is correlated with covalently closed circular DNA, the $\mathrm{HBsAg}$ titer might be a good indicator of the off-treatment response. This study aimed to determine the relationship between the HBsAg titer and the entecavir (ETV) off-treatment response.

Methods: This study analyzed 44 consecutive CHB patients (age, 44.6 \pm 11.4 years, mean \pm SD; men, $63.6 \%$; positive hepatitis B envelope antigen (HBeAg) at baseline, 56.8\%; HBV DNA level, $6.8 \pm 1.3 \log _{10} \mathrm{IU} / \mathrm{mL}$ ) treated with ETV for a sufficient duration and in whom treatment was discontinued after $\mathrm{HBsAg}$ levels were measured. A virological relapse was defined as an increase in serum HBV DNA level of $>2000 \mathrm{IU} / \mathrm{mL}$, and a clinical relapse was defined as a virological relapse with a biochemical flare, defined as an increase in the serum alanine aminotransferase level of $>2 \times$ upper limit of normal.

Results: After stopping ETV, virological relapse and clinical relapse were observed in 32 and 24 patients, respectively, during $20.8 \pm 19.9$ months of follow-up. The cumulative incidence rates of virological relapse were $36.2 \%$ and $66.2 \%$, respectively, at 6 and 12 months, and those of clinical relapse were $14.3 \%$ and $42.3 \%$. The off-treatment HBsAg level was an independent factor associated with clinical relapse (hazard ratio, 2.251; 95\% confidence interval, 1.076-4.706; $P=0.031$ ). When patients were grouped according to off-treatment $\mathrm{HBsAg}$ levels, clinical relapse did not occur in patients with an off-treatment $\mathrm{HBsAg}$ level of $\leq 2 \log _{10} \mathrm{IU} / \mathrm{mL}(\mathrm{n}=5)$, while the incidence rates of clinical relapse at 12 months after off-treatment were $28.4 \%$ and $55.7 \%$ in patients with off-treatment HBsAg levels of $>2$ and $\leq 3 \log _{10} \mathrm{IU} / \mathrm{mL}(n=11)$ and $>3$ $\log _{10} \mathrm{IU} / \mathrm{mL}(\mathrm{n}=28)$, respectively.

Conclusions: The off-treatment $\mathrm{HBsAg}$ level is closely related to clinical relapse after treatment cessation. A serum $\mathrm{HBsAg}$ level of $<2 \log _{10} \mathrm{IU} / \mathrm{mL}$ is an excellent predictor of a sustained off-treatment response in CHB patients who have received ETV for a sufficient duration. (Clin Mol Hepatol 2016;22:382-389)

Keywords: Hepatitis B virus; Hepatitis B surface antigen; Relapse; Off-treatment

\section{Abbreviations:}

ALT, alanine aminotransferase; APASL, the Asian Pacific Association for the Study of the Liver; BMI, body mass index; $C H B$, chronic hepatitis B; ETV, entecavir; $\mathrm{HBeAg}$, hepatitis B e antigen; $\mathrm{HBs} A g$, hepatitis B surface antigen; $\mathrm{HBV}$, hepatitis $B$ virus; $\mathrm{HCC}$, hepatocellular carcinoma; INR, international normalized ratio; NAs, nucleos $(t) i d e$ analogues

\section{Corresponding author: Yeon Seok Seo}

Division of Gastroenterology and Hepatology, Department of Internal Medicine, Korea University College of Medicine, 73 Inchon-ro, Seongbukgu, Seoul 02841, Korea

Tel: +82-2-920-6608, Fax: +82-2-953-1943

E-mail: drseo@korea.ac.kr 
Han Ah Lee, et al. $\mathrm{HBsAg}$ titer for ETV off-treatment in CHB

\section{INTRODUCTION}

Chronic hepatitis B (CHB) is the leading cause of liver cirrhosis and hepatocellular carcinoma (HCC) worldwide, especially in Asia.' Since the replication of the hepatitis B virus (HBV) and the subsequent immune response are the main mechanisms by which chronic intrahepatic necroinflammation, progressive fibrosis, and liver cirrhosis develop, most practice guidelines recommend achieving long-term suppression of viral replication in CHB patients. $^{2-4}$

With the development of effective oral nucleos(t)ide analogues (NAs), prognosis of patients with CHB has improved significantly. NAs with a high potency and high genetic barrier, such as entecavir (ETV) or tenofovir disoproxil fumarate, effectively suppress HBV replication and hepatic necroinflammation, and they prevent disease progression and the development of complications. ${ }^{5-8}$ However, the optimal duration of treatment is not clearly defined. The Western practice guidelines recommend long-term maintenance of NA treatment until the patient achieves hepatitis B surface antigen ( $\mathrm{HBSAg}$ ) seroclearance. ${ }^{2,9}$ Considering the low incidence of HBsAg seroclearance following NA treatment ${ }^{10-12}$ and the high relapse rate following the discontinuation of NA without HBsAg seroclearance, ${ }^{13-16}$ long-term treatment with NA is required in most CHB patients.

Recent studies have identified predictors of sustained off-treatment response following NA cessation, such as younger age, ${ }^{17,18}$ low alanine aminotransferase (ALT) $)^{19}$ and HBV DNA ${ }^{20}$ levels at baseline, and the duration of consolidation treatment. ${ }^{21-25}$ Discrepant predictive values have been noted among various studies depending on the type of NA used, the criteria for the discontinuation of treatment, and the definition of relapse. In addition, the Asian Pacific Association for the Study of the Liver (APASL) recommends the discontinuation of NAs at 12 months of consolidation treatment after hepatitis B envelope antigen (HBeAg) seroconversion in $\mathrm{HBeAg}$-positive patients, and at 12 months of consolidation treatment after achieving undetectable HBV DNA in HBeAg-negative patients. ${ }^{3}$ However, CHB relapse occurs in most patients even though treatment is discontinued in accordance with this recommendation. ${ }^{23,24}$

The serum HBsAg level correlates with the level of intrahepatic covalently closed circular DNA. ${ }^{26,27}$ Furthermore, over the natural history of $\mathrm{CHB}$, a low serum HBsAg level has been associated with improved immune-mediated viral clearance. ${ }^{28,29}$ Therefore, serum HBsAg level could be a good predictor of sustained offtreatment response after NA cessation. Several studies have eval- uated the efficacy of serum HBsAg level for predicting sustained responses following NA cessationbut the results have been conflicting so far. While some studies have validated serum HBsAg level as a predictor for sustained response, ${ }^{30-34}$ others have failed to demonstrate a relationship between serum HBsAg level and sustained off-treatment response. ${ }^{20,35,36}$ Therefore, this study aimed to evaluate the efficacy of using the serum HBsAg level in predicting sustained off-treatment responses in ETV-treated CHB patients.

\section{METHODS}

\section{Patients}

Consecutive CHB patients who were treated with ETV for a sufficient duration and for whom treatment was thereafter discontinued after measuring serum HBsAg levels were included in this study. Patients with a previous history of treatment with NAs before ETV treatment or patients with HCC at the time of ETV initiation were excluded. CHB was defined as a positive serological test for serum HBsAg for at least 6 months. Virologic response was defined as a decrease in serum HBV DNA to undetectable levels by PCR assays. ${ }^{9}$ Sufficient treatment duration was defined as $\geq 12$ months of consolidation treatment after serum HBeAg clearance and virologic response in HBeAg-positive CHB patients and as $\geq 12$ months of consolidation treatment after virologic response in HBeAg-negative CHB patients. Liver cirrhosis was diagnosed based on histology and/or imaging studies. The study protocol conformed to the ethical guidelines of the 1975 Helsinki Declaration and was approved by the Institutional Review Board (No: ED16137). A waiver of consent was obtained and the patient records were anonymized and de-identified prior to analysis.

\section{Data collection}

Clinical data including age, sex, daily alcohol consumption amount, and history of diabetes and hypertension were collected for each patient. Results of the laboratory tests (i.e., platelet count, international normalized ratio [INR], serum ALT, bilirubin, albumin, creatinine, and HBV DNA levels, and serum HBeAg/Ab) were collected at the time of ETV initiation. The duration of ETV treatment, the duration of consolidation treatment, the time of virological relapse, and the time of clinical relapse were also collected. The serum HBsAg level was measured at the end-of-treatment using the 
Architect HBsAg QT chemiluminescent microparticle immunoassay (Abbott Laboratories, Abbott Park, IL, USA). Laboratory tests, including serum HBV DNA and ALT levels, were performed for all patients every 3-6 months after the end-of-treatment. Patients were evaluated more often when clinically indicated. Virological relapse was defined as an increase in the serum HBV DNA level $>2000 \mathrm{IU} / \mathrm{mL}$, while clinical relapse was defined as a serum ALT level elevation $>2 \times$ upper limit of normal in addition to HBV DNA level $>2000 \mathrm{lU} / \mathrm{mL}^{20}$

\section{Statistics}

Statistical analyses were performed using SPSS software version 20.0 (SPSS Inc., Chicago, IL, USA). Data were expressed as the mean \pm standard deviation or number (\%). The Mann-Whitney $U$ test and chi-square test were used to compare continuous and categorical variables, respectively. The cumulative virological relapse rate was determined by the Kaplan-Meier method, and the difference between groups was determined by the log lank test. The Cox proportion hazard model was utilized to analyze factors associated with relapse. Significant factors $(P<0.1)$ in the univariate analysis were subjected to multivariate analysis to determine independent predictive factors. All tests were two-tailed, and $P$ values $<0.05$ were considered statistically significant.

\section{RESULTS}

\section{Baseline characteristics}

Baseline characteristics are presented in Table 1. A total of 44 CHB patients were included in this study. The study population had a mean age of $44.6 \pm 11.4$ years and 28 patients (63.6\%) were men. Liver cirrhosis was diagnosed in 17 patients (38.6\%). At the time of treatment initiation, serum HBeAg was positive in 25 patients (56.8\%) and the mean serum HBV DNA level was 6.8 21.3 $\log _{10} \mathrm{IU} / \mathrm{mL}$. Furthermore, the serum HBV DNA level was $<7 \log _{10}$ $\mathrm{IU} / \mathrm{mL}$ in 22 patients (50.0\%), while it was $\geq 7 \log _{10} \mathrm{IU} / \mathrm{mL}$ in 22 patients (50.0\%). The serum HBV DNA level was significantly higher in $\mathrm{HBeAg}$-positive patients than in $\mathrm{HBeAg}$-negative patients (7.2 $2 \pm 1.0$ vs. $\left.6.2 \pm 1.5 \log _{10} \mathrm{IU} / \mathrm{mL}, P=0.011\right)$, while other characteristics did not differ significantly between the two groups.

\section{On-treatment virological response}

Serum HBV DNA became undetectable in all enrolled patients and the mean time to undetectable HBV DNA was 5.4 \pm 0.4 months (median, 5.5 months). Serum HBV DNA became undetectable within 3 months, 3-6 months, and $>6$ months in 14 (31.8\%), $24(43.4 \%)$, and $6(13.6 \%)$ patients, respectively. The time to undetectable HBV DNA did not differ between HBeAg-positive and HBeAg-negative CHB patients $(P=0.222)$.

Table 1. Baseline characteristics of all enrolled patients with CHB according to the serum HBeAg level at the time of ETV treatment initiation

\begin{tabular}{|c|c|c|c|c|}
\hline & $\begin{array}{l}\text { All patients } \\
\quad(n=44)\end{array}$ & $\begin{array}{l}\text { HBeAg-positive patients } \\
\qquad(n=25)\end{array}$ & $\begin{array}{l}\text { HBeAg-negative } \\
\text { patients }(n=19)\end{array}$ & $P$-value \\
\hline Age, years & $44.6 \pm 11.4$ & $44.6 \pm 13.0$ & $44.7 \pm 9.3$ & 0.969 \\
\hline Male, n (\%) & $28(63.6)$ & $14(56.0)$ & $14(73.7)$ & 0.227 \\
\hline $\mathrm{BMI}, \mathrm{kg} / \mathrm{m}^{2}$ & $23.5 \pm 2.7$ & $23.6 \pm 3.2$ & $23.5 \pm 2.2$ & 0.936 \\
\hline Diabetes, n (\%) & $4(9.1)$ & $1(4.0)$ & $3(15.8)$ & 0.178 \\
\hline Hypertension, n (\%) & $5(11.4)$ & $2(8.0)$ & $3(15.8)$ & 0.420 \\
\hline Cirrhosis, n (\%) & $17(38.6)$ & $10(40.0)$ & $7(36.8)$ & 0.831 \\
\hline $\mathrm{ALT}, \mathrm{IU} / \mathrm{mL}$ & $260.7 \pm 423.9$ & $202.0 \pm 197.6$ & $338.0 \pm 605.1$ & 0.297 \\
\hline Bilirubin, mg/dL & $2.4 \pm 5.4$ & $2.6 \pm 6.7$ & $2.2 \pm 2.8$ & 0.827 \\
\hline Albumin, g/dL & $4.0 \pm 0.6$ & $4.0 \pm 0.6$ & $4.1 \pm 0.6$ & 0.562 \\
\hline Platelet count, $\times 10^{9} / \mathrm{L}$ & $146.0 \pm 63.6$ & $152.8 \pm 55.6$ & $137.0 \pm 73.5$ & 0.419 \\
\hline Prothrombin time, INR & $1.2 \pm 0.3$ & $1.2 \pm 0.4$ & $1.1 \pm 0.2$ & 0.559 \\
\hline Creatinine, mg/dL & $0.9 \pm 0.2$ & $0.8 \pm 0.2$ & $0.9 \pm 0.2$ & 0.227 \\
\hline HBV DNA, $\log _{10} I \mathrm{I} / \mathrm{mL}$ & $6.8 \pm 1.3$ & $7.2 \pm 1.0$ & $6.2 \pm 1.5$ & 0.011 \\
\hline
\end{tabular}

Values are expressed as mean \pm standard deviation or number (percent).

BMI, body mass index; ALT, alanine aminotransferase; INR, international normalized ratio; HBeAg, hepatitis B envelope antigen; $H B V$, hepatitis $B$ virus. 
Serum HBeAg was cleared in all HBeAg-positive patients and the mean time to HBeAg clearance was 13.6 2 2.7 months (median, 9.8 months). HBeAg seroconversion was achieved in 7 of the $25 \mathrm{HBeAg}$-positive patients and the mean time to HBeAg seroconversion was $57.9 \pm 6.6$ months.

\section{Clinical course after the end-of-treatment}

ETV was discontinued after $34.7 \pm 19.0$ months of treatment (37.0 \pm 20.2 months and 31.6 \pm 17.4 months in HBeAg-positive and $\mathrm{HBeAg}$-negative patients, respectively; $P=0.356)$. ETV was continued for $29.3 \pm 18.6$ months after undetectable HBV DNA in all enrolled patients $(31.0 \pm 19.5$ months and $27.1 \pm 17.7$ months in $\mathrm{HBeAg}$-positive and $\mathrm{HBeAg}$-negative patients, respectively; $P=0.50)$ and for $23.4 \pm 16.1$ months after HBeAg clearance in $\mathrm{HBeAg}$-positive patients. The duration of consolidation treatment was $25.0 \pm 16.7$ months, which did not differ between the HBeAgpositive and $\mathrm{HBeAg}$-negative patients $(23.4 \pm 16.1$ months vs. $27.1 \pm 17.7$ months, $P=0.475$ ).

Serum HBsAg level at the end-of-treatment was $3.0 \pm 1.0 \log _{10}$ $\mathrm{IU} / \mathrm{mL}$. Serum HBsAg levelswere $\leq 2,>2 \leq 3$, and $>3 \log _{10} \mathrm{IU} / \mathrm{mL}$ in $5(11.4 \%), 11(25.0 \%)$, and $28(63.6 \%)$ patients, respectively. The proportion of patients with an end-of-treatment HBsAg level of $>3 \log _{10} \mathrm{IU} / \mathrm{mL}$ was significantly higher in patients with positive HBeAg at baseline (20 of 25 patients, 80.0\%) compared with those with negative HBeAg at baseline (8 of 19 patients, 42.1\%;
$P=0.010)$. In addition, the proportion of patients with an end-oftreatment HBsAg level of $>3 \log _{10} \mathrm{IU} / \mathrm{mL}$ was significantly higher in patients with baseline HBV DNA $>7 \log _{10} \mathrm{IU} / \mathrm{mL}$ (19 of 22 patients, $86.4 \%$ ) compared to those with baseline HBV DNA $\leq 7$ $\log _{10} \mathrm{IU} / \mathrm{mL}$ (9 of 22 patients, $40.9 \% ; P=0.004$ ).

During a follow-up period of $20.8 \pm 19.9$ months after the endof-treatment, virological relapse was observed in 32 patients (20 and 12 patients whose baseline HBeAg was positive and negative, respectively). The cumulative virological relapse rates at 6 , 12 , and 24 months were $36.2 \%, 66.2 \%$, and $77.3 \%$, respectively (Fig. 1A). Clinical relapse was observed in 24 patients (16 HBeAgpositive patients and $8 \mathrm{HBeAg}$-negative patients). The cumulative clinical relapse rates at 6,12 , and 24 months were $14.3 \%, 42.3 \%$, and $58.5 \%$, respectively (Fig. $1 \mathrm{~B}$ ).

Clinical relapse occurred more frequently in the $\mathrm{HBeAg}$-positive patients compared to the HBeAg-negative patients ( $P=0.049$; Fig. $2 A)$. The cumulative clinical relapse rates at 6,12 , and 24 months were $16.7 \%, 57.9 \%$, and $73.7 \%$, respectively, in the HBeAg-positive patients and $11.1 \%, 23.0 \%$, and $37.7 \%$, respectively, in the $\mathrm{HBeAg-negative} \mathrm{patients.} \mathrm{The} \mathrm{incidence} \mathrm{of} \mathrm{clinical} \mathrm{relapse} \mathrm{differed}$ significantly according to the serum HBV DNA levels at the time of ETV initiation ( $P=0.038$; Fig. $2 B$ ). The cumulative incidence of clinical relapse rates at 6, 12, and 24 months were $14.3 \%, 25.4 \%$, and $37.4 \%$, respectively, in patients with a baseline HBV DNA level $<7 \log _{10} \mathrm{IU} / \mathrm{mL}$ and $14.3 \%, 57.1 \%$, and $78.6 \%$, respectively, in patients with a baseline HBV DNA level $\geq 7 \log _{10} \mathrm{IU} / \mathrm{mL}$. Further-
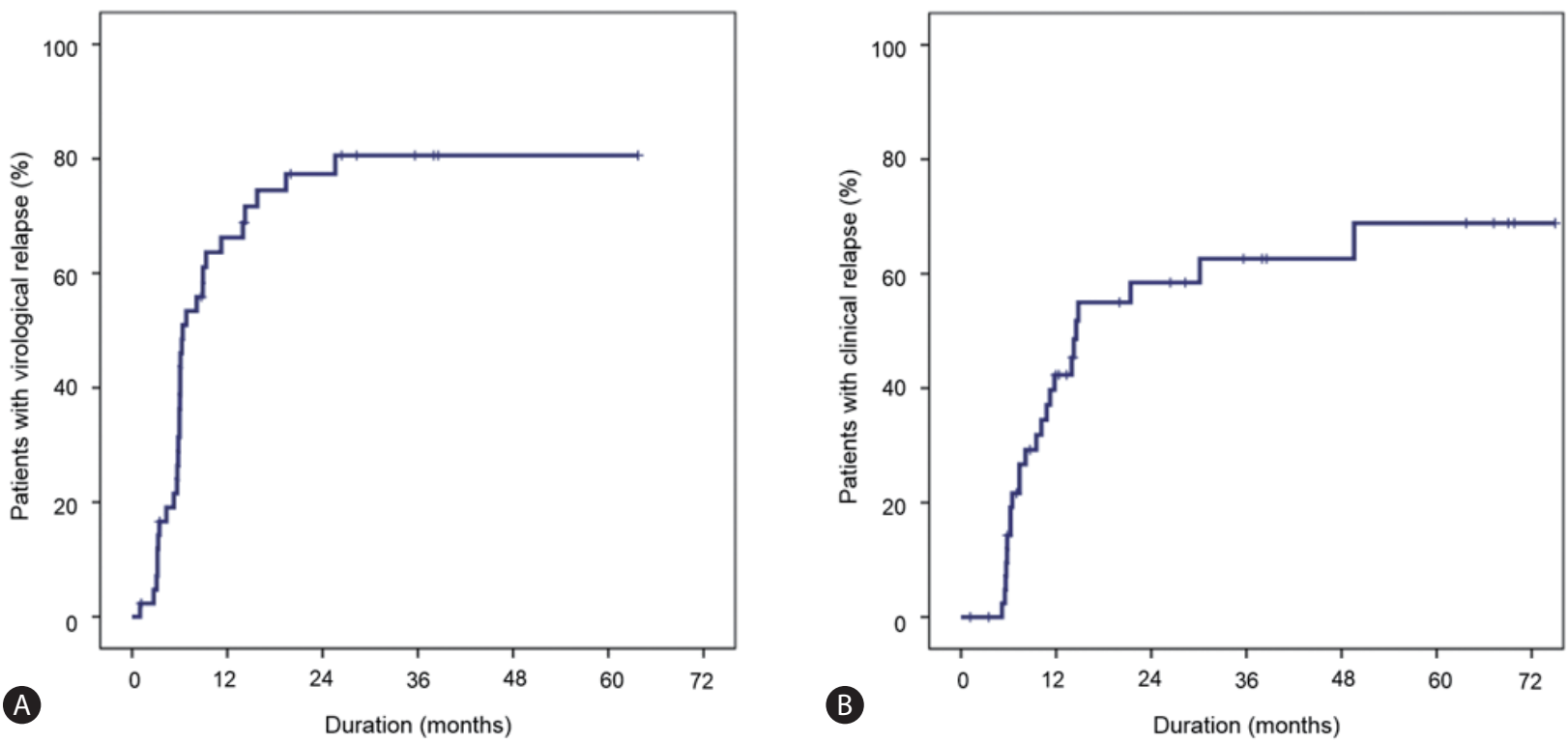

Figure 1. Cumulative incidence of virological relapse (A) and clinical relapse (B). 
more, the incidence of clinical relapse differed significantly according to the end-of-treatment serum HBsAg levels ( $P=0.010$; Fig. 2C). Clinical relapse did not occur in patients with end-oftreatment HBsAg levels of $\leq 2 \log _{10} \mathrm{IU} / \mathrm{mL}$, while the incidence rates of clinical relapse at 6,12 , and 24 months after end-of- treatment were $18.2 \%, 28.4 \%$, and $28.4 \%$, respectively, in patients with end-of-treatment HBsAg levels of $>2$ and $\leq 3 \log _{10}$ IU/ $\mathrm{mL}$ and $15.4 \%, 55.7 \%$, and $83.4 \%$, respectively, in patients with end-of-treatment HBsAg levels of $>3 \log _{10} \mathrm{IU} / \mathrm{mL}$.

Of 24 patients with clinical relapse, ETV therapy was resumed
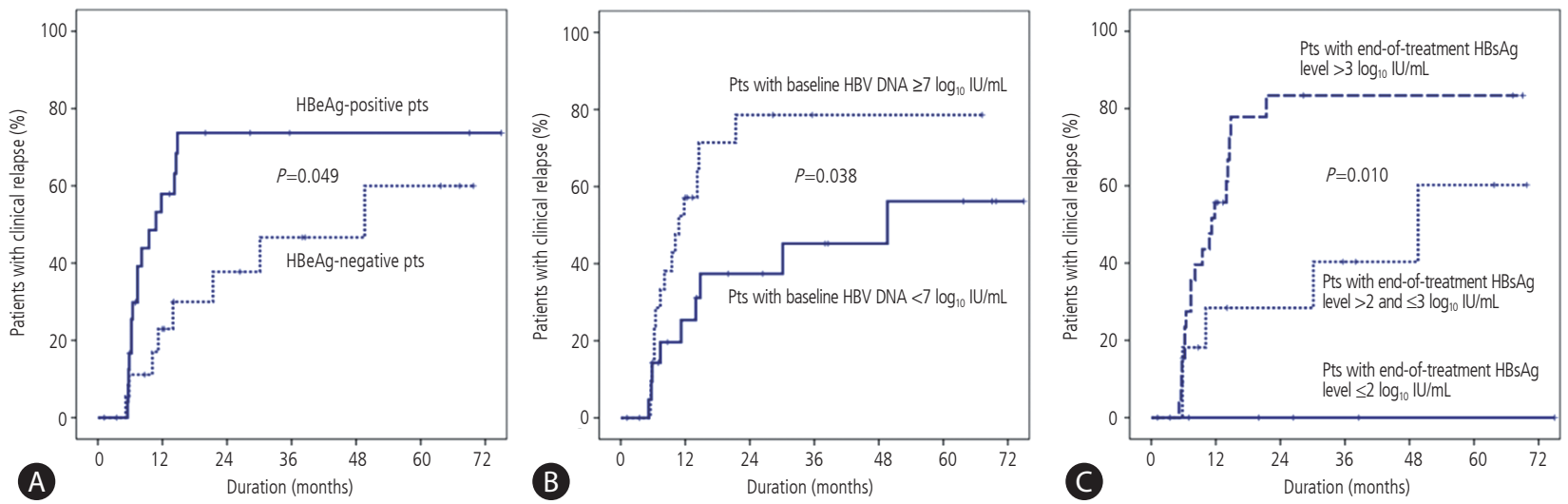

Figure 2. Cumulative incidence of clinical relapse according to the baseline serum HBeAg level (A), baseline serum HBV DNA level (B), and end-oftreatment HBsAg level (C).

Table 2. Factors associated with the development of clinical relapse

\begin{tabular}{|c|c|c|c|c|}
\hline \multirow{2}{*}{ Variable } & \multicolumn{2}{|c|}{ Univariate } & \multicolumn{2}{|c|}{ Multivariate } \\
\hline & HR $(95 \% \mathrm{CI})$ & $P$-value & HR $(95 \% \mathrm{CI})$ & $P$-value \\
\hline Age (years) & $1.026(0.988-1.066)$ & 0.177 & & \\
\hline Male (vs. female) & $0.576(0.254-1.303)$ & 0.185 & & \\
\hline $\mathrm{BMI}\left(\mathrm{kg} / \mathrm{m}^{2}\right)$ & $0.951(0.808-1.120)$ & 0.549 & & \\
\hline Diabetes (yes vs. no) & $0.295(0.040-2.190)$ & 0.233 & & \\
\hline Hypertension (yes vs. no) & $1.195(0.407-3.510)$ & 0.746 & & \\
\hline Liver cirrhosis (yes vs. no) & $0.528(0.208-1.341)$ & 0.179 & & \\
\hline Platelet count $\left(\times 10^{9} / \mathrm{L}\right)$ & $0.998(0.992-1.004)$ & 0.607 & & \\
\hline Prothrombin time, INR & $0.212(0.023-1.982)$ & 0.174 & & \\
\hline Albumin (g/dL) & 1.025 (0.540-1.944) & 0.941 & & \\
\hline Bilirubin (mg/dL) & $0.822(0.630-1.071)$ & 0.147 & & \\
\hline ALT (IU/L) & $1.000(0.998-1.001)$ & 0.560 & & \\
\hline Creatinine (mg/dL) & $0.427(0.045-4.034)$ & 0.458 & & \\
\hline HBeAg (positive vs. negative) & $2.315(0.980-5.470)$ & 0.056 & $1.791(0.703-4.564)$ & 0.222 \\
\hline HBV DNA $\left(\log _{10} \mid \mathrm{U} / \mathrm{mL}\right)$ & 1.399 (0.982-1.992) & 0.063 & $1.022(0.671-1.557)$ & 0.920 \\
\hline Duration of treatment (months) & $0.997(0.975-1.021)$ & 0.828 & & \\
\hline Time to HBeAg loss (months) & $0.983(0.945-1.022)$ & 0.381 & & \\
\hline HBeAg seroconversion (yes vs. no) & $0.981(0.314-3.070)$ & 0.974 & & \\
\hline Duration of consolidation treatment (months) & $0.995(0.968-1.022)$ & 0.721 & & \\
\hline End-of-treatment HBsAg level $\left(\log _{10} \mathrm{IU} / \mathrm{mL}\right)$ & $2.606(1.278-5.311)$ & 0.008 & $2.251(1.076-4.706)$ & 0.031 \\
\hline
\end{tabular}

$H R$, hazard ratio; $\mathrm{Cl}$, confidence interval; BMI, body mass index; INR, international normalized ratio; ALT, alanine aminotransferase; HBeAg, hepatitis B e antigen; HBV, hepatitis B virus, HBsAg, hepatitis B surface antigen. 
Han Ah Lee, et al. $\mathrm{HBsAg}$ titer for ETV off-treatment in CHB

after clinical relapse in all patients except one patient who was lost to follow-up after development of clinical relapse.

\section{Predictive factors for clinical relapse}

A univariate analysis revealed a trend of increased clinical relapse risk with positive serum $\mathrm{HBeAg}(P=0.056)$ and higher HBV DNA levels $(P=0.063)$, while the serum HBsAg level was significantly associated with the development of clinical relapse $(P=0.008$; Table 2). Other variables including age, sex, and duration of consolidation treatment were not associated with the development of clinical relapse.

Multivariate analysis indicated that the serum HBsAg level was the only independent predictor of clinical relapse $(\beta, 0.811$; hazard ratio $\left.(H R], 2.251 ; 95 \% \mathrm{Cl}_{1} 1.076-4.706 ; P=0.031\right)$, while HBeAg $(\beta, 0.583 ; \mathrm{HR}, 1.791 ; 95 \% \mathrm{Cl}, 0.703-4.564 ; P=0.222)$ and HBV DNA levels $(\beta, 0.022 ; H R, 1.022 ; 95 \% \mathrm{Cl}, 0.671-1.557$; $P=0.920$ ) were not significantly associated with the development of clinical relapse.

\section{DISCUSSION}

Although various studies have evaluated the predictive efficacy of the serum HBsAg level for a sustained off-treatment response, the efficacy is not clearly defined due to discrepant results. While some studies have reported that the serum HBsAg level is a good predictor for sustained response, ${ }^{30-32}$ other studies have not. ${ }^{20,35,36}$ These discrepancies are not surprising since the type of NA used, duration of NA treatment, duration of consolidation treatment, and the definition of relapse differ across these studies. ${ }^{20,30-32,35,36}$ We evaluated the predictive efficacy of the end-of-treatment HBsAg level in patients treated for a sufficient duration with ETV and report that the serum HBsAg level is an excellent predictor for sustained off-treatment response. Patients with end-of-treatment serum HBsAg levels of $\leq 2 \log _{10} \mathrm{IU} / \mathrm{mL}$ showed a sustained response after discontinuation of ETV, which is consistent with previous studies. ${ }^{30-32}$ Therefore, monitoring the serum HBsAg level may be useful for determining an optimal time for treatment discontinuation in patients who were treated with NAs for a sufficient duration.

There were some discrepancies between previous results and our results regarding significant predictors for sustained off-treatment response. Although the principle reasons for these discrepancies could be the different types of NAs used, different treat- ment discontinuation criteria, and the definition of relapse among the various studies, additional factors may be involved. First, previous studies have suggested that a younger age is a significant predictor for a sustained response, ${ }^{17,18}$ but, we did not find any relationship between age and a sustained response. Although previous studies have shown a significantly lower relapse rate in patients less than 20 years $^{17}$ or 25 years of age, ${ }^{18}$ all enrolled patients in our study were 20 years or older, with only one patient being $<25$ years old. Furthermore, previous studies also reported that a lower baseline serum HBV DNA level is a significant predictor for sustained response, ${ }^{20,23,24}$ but the baseline HBV DNA level was not found to be associated with virological relapse in another study. ${ }^{31}$

A previous study reported that the cut-off value of the serum HBV DNA level for predicting relapse as $2 \times 10^{5} \mathrm{IU} / \mathrm{mL}$; however, we could not use this cut-off value as only five patients in our study group had a serum HBV DNA level $<2 \times 10^{5} \mathrm{IU} / \mathrm{mL}$. We instead used the median HBV DNA level $\left(7 \log _{10} \mathrm{IU} / \mathrm{mL}\right)$ as the cutoff value in our study. Even as the clinical relapse frequency was significantly higher in patients with baseline serum HBV DNA level of $\geq 7 \log _{10} \mathrm{IU} / \mathrm{mL}$, the baseline serum HBV DNA level was not significantly associated with the development of clinical relapse, as indicated by a multivariate analysis. This could be explained by the results of the end-of-treatment serum HBsAg level according to the baseline HBV DNA level.

Various previous studies have also suggested that a sufficient duration of consolidation treatment is required to achieve a sustained off-treatment response. ${ }^{21-25}$ However, the duration of consolidation treatment was not related with a sustained response in this study. This could be due to the definition of sufficient duration of treatment in this study. All patients in this study were treated with ETV for more than 12 months after serum $\mathrm{HBeAg}$ clearance and virologic response in $\mathrm{HBeAg}$-positive $\mathrm{CHB}$ patients and virologic response in $\mathrm{HBeAg}$-negative patients. Previous studies have reported that prolonging the consolidation of treatment did not additionally improve the relapse rate. ${ }^{20,22,31}$

There are discrepancies in the stopping rule used in this study and that of current practice guidelines. ${ }^{2-4}$ First, ETV was discontinued in patients with ETV $\geq 12$ months of consolidation treatment after serum $\mathrm{HBeAg}$ clearance and a virologic response in $\mathrm{HBeAg}$ positive CHB patients in this study, while current practice guidelines recommend the discontinuation of NA treatment in patients who have achieved an undetectable serum HBV DNA level and, not $\mathrm{HBeAg}$ seroclearance, but $\mathrm{HBeAg}$ seroconversion in patients with a positive $\mathrm{HBeAg}$ at baseline. ${ }^{2-4}$ However, HBeAg seroconver- 
sion is rare in patients with genotype C CHB compared to those with other genotypes. ${ }^{37}$ In addition, in a previous Korean study, both $\mathrm{HBeAg}$ seroclearance and seroconversion were appropriate parameters for the discontinuation of NA. ${ }^{21}$ Second, ETV was discontinued in patients with $\geq 12$ months of consolidation treatment after virologic response in $\mathrm{HBeAg}$-negative $\mathrm{CHB}$ patients in this study, while the APASL guideline recommends considering discontinuation of NAs in patients who have been treated for at least two years and have an undetectable level of HBV DNA. ${ }^{3}$ However, this recommendation of duration of consolidation treatment was produced by the opinion of experts, and not by evidence. ${ }^{3}$ Furthermore, the duration of the consolidation period was not associated with the development of clinical relapse in this study. Finally, $38.6 \%$ of patients included in this study had liver cirrhosis, while several practice guidelines recommend indefinite antiviral treatment in patients with liver cirrhosis because of the risk of hepatic decompensation or mortality after reactivation. ${ }^{2,4}$ Although some patients in this study were combined with liver cirrhosis, their liver functions were absolutely normal at the time of end-oftreatment and there was no serious events in these patients. Similar to this study, $14-41 \%$ of patients with liver cirrhosis were included in previous studies. $20,33,34$

There are several limitations in this study. First, the serum HBsAg level was not measured at the time of NA initiation as the test was not available. Analyses of baseline HBsAg level and its kinetics during treatment would have provided additional information, as a previous study has found a correlation between HBsAg kinetics and sustained off-treatment response in HBeAg-positive patients. ${ }^{30}$ Second, this study was performed retrospectively, and although we enrolled all patients who met the inclusion criteria and tried to avoid a selection bias, it may not have not been sufficient. Finally, the sample size in our study was too small to confirm our results and large scale prospective studies are still needed to confirm the predictive efficacy of serum HBsAg level.

In conclusion, the serum HBsAg level at the end-of-treatment was closely related with off-treatment clinical relapse. Furthermore, a serum HBsAg level $\leq 2 \log _{10} \mathrm{IU} / \mathrm{mL}$ is an excellent predictor for sustained off-treatment response in CHB patients who had received ETV for a sufficient duration.

\section{Funding support}

This study was supported by the Research Supporting Program of the Korean Association for the Study of the Liver and by a grant from the Korean Healthcare Technology R\&D Project, Ministry of Health and Welfare, Korea (HI10C2020).

\section{Conflicts of Interest}

The authors have no conflicts to disclose.

\section{REFERENCES}

1. Chan HL, Sung JJ. Hepatocellular carcinoma and hepatitis B virus. Semin Liver Dis 2006;26:153-161.

2. European Association For The Study Of The Liver. EASL clinical practice guidelines: Management of chronic hepatitis B virus infection. J Hepatol 2012;57:167-185.

3. Liaw YF, Kao JH, Piratvisuth T, Chan HL, Chien RN, Liu CJ, et al. Asian-Pacific consensus statement on the management of chronic hepatitis B: a 2012 update. Hepatol Int 2012;6:531-561.

4. Terrault NA, Bzowej NH, Chang KM, Hwang JP, Jonas MM, Murad $\mathrm{MH}$, et al. AASLD guidelines for treatment of chronic hepatitis $\mathrm{B}$. Hepatology 2016;63:261-283.

5. Liaw YF, Sung JJ, Chow WC, Farrell G, Lee CZ, Yuen H, et al. Lamivudine for patients with chronic hepatitis $B$ and advanced liver disease. N Engl J Med 2004;351:1521-1531.

6. Liaw YF, Raptopoulou-Gigi M, Cheinquer H, Sarin SK, Tanwandee $T$, Leung $N$, et al. Efficacy and safety of entecavir versus adefovir in chronic hepatitis B patients with hepatic decompensation: a randomized, open-label study. Hepatology 2011;54:91-100.

7. Kim YJ, Kim K, Hwang SH, Kim SS, Lee D, Cheong JY, et al. Durability after discontinuation of nucleos(t)ide therapy in chronic $\mathrm{HBeAg}$ negative hepatitis patients. Clin Mol Hepatol 2013;19:300-304.

8. Lok AS, McMahon BJ, Brown RS Jr, Wong JB, Ahmed AT, Farah W, et al. Antiviral therapy for chronic hepatitis B viral infection in adults: A systematic review and meta-analysis. Hepatology 2016;63:284-306.

9. Lok AS, McMahon BJ. Chronic hepatitis B: update 2009. Hepatology 2009;50:661-662.

10. Marcellin P, Gane E, Buti M, Afdhal N, Sievert W, Jacobson IM, et al. Regression of cirrhosis during treatment with tenofovir disoproxil fumarate for chronic hepatitis B: a 5-year open-label follow-up study. Lancet 2013;381:468-475.

11. Seto WK, Wong DK, Fung J, Huang FY, Lai CL, Yuen MF. Reduction of hepatitis $B$ surface antigen levels and hepatitis $B$ surface antigen seroclearance in chronic hepatitis $B$ patients receiving 10 years of nucleoside analogue therapy. Hepatology 2013;58:923-931.

12. Hadziyannis SJ, Tassopoulos NC, Heathcote EJ, Chang TT, Kitis G, Rizzetto $M$, et al. Long-term therapy with adefovir dipivoxil for HBeAg-negative chronic hepatitis B for up to 5 years. Gastroenterology 2006;131:1743-1751

13. Song BC, Suh DJ, Lee HC, Chung YH, Lee YS. Hepatitis B e antigen seroconversion after lamivudine therapy is not durable in patients with chronic hepatitis B in Korea. Hepatology 2000;32:803-806.

14. Lee CM, Ong GY, Lu SN, Wang JH, Liao CA, Tung HD, et al. Durabil- 
Han Ah Lee, et al. $\mathrm{HBsAg}$ titer for ETV off-treatment in CHB

ity of lamivudine-induced HBeAg seroconversion for chronic hepatitis B patients with acute exacerbation. J Hepatol 2002;37:669-674.

15. Ahn SH, Chan HL, Chen PJ, Cheng J, Goenka MK, Hou J, et al. Chronic hepatitis B: whom to treat and for how long? Propositions, challenges, and future directions. Hepatol Int 2010;4:386-395.

16. Van Nunen $A B$, Hansen BE, Suh DJ, Löhr HF, Chemello L, Fontaine $H$, et al. Durability of $\mathrm{HBeAg}$ seroconversion following antiviral therapy for chronic hepatitis $B$ : relation to type of therapy and pretreatment serum hepatitis B virus DNA and alanine aminotransferase. Gut 2003:52:420-424.

17. Liu F, Wang L, Li XY, Liu YD, Wang JB, Zhang ZH, et al. Poor durability of lamivudine effectiveness despite stringent cessation criteria: a prospective clinical study in hepatitis B e antigen-negative chronic hepatitis B patients. J Gastroenterol Hepatol 2011;26:456-460.

18. Ha M, Zhang $G$, Diao $S$, Lin $M$, Sun $L$, She $H$, et al. A prospective clinical study in hepatitis $B$ e antigen-negative chronic hepatitis $B$ patients with stringent cessation criteria for adefovir. Arch Virol 2012;157:285-290.

19. Patwardhan VR, Sengupta N, Bonder A, Lau D, Afdhal NH. Treatment cessation in noncirrhotic, e-antigen negative chronic hepatitis $B$ is safe and effective following prolonged anti-viral suppression with nucleosides/nucleotides. Aliment Pharmacol Ther 2014;40:804-810.

20. Jeng WJ, Sheen IS, Chen YC, Hsu CW, Chien RN, Chu CM, et al. Off-therapy durability of response to entecavir therapy in hepatitis B e antigen-negative chronic hepatitis B patients. Hepatology 2013;58:1888-1896.

21. Lee HW, Lee HJ, Hwang JS, Sohn JH, Jang JY, Han KJ, et al. Lamivudine maintenance beyond one year after $\mathrm{HBeAg}$ seroconversion is a major factor for sustained virologic response in $\mathrm{HBeAg}$-positive chronic hepatitis B. Hepatology 2010;51:415-421.

22. Pan X, Zhang K, Yang X, Liang J, Sun H, Li X, et al. Relapse rate and associated-factor of recurrence after stopping NUCs therapy with different prolonged consolidation therapy in $\mathrm{HBeAg}$ positive $\mathrm{CHB}$ patients. PLoS One 2013;8:e68568.

23. Yeh CT, Hsu CW, Chen YC, Liaw YF. Withdrawal of lamivudine in HBeAg-positive chronic hepatitis B patients after achieving effective maintained virological suppression. J Clin Virol 2009;45:114-118.

24. Fung J, Lai CL, Tanaka Y, Mizokami M, Yuen J, Wong DK, et al. The duration of lamivudine therapy for chronic hepatitis $B$ : cessation vs. continuation of treatment after HBeAg seroconversion. Am J Gastroenterol 2009;104:1940-1946.

25. Reijnders JG, Perquin MJ, Zhang N, Hansen BE, Janssen HL. Nucleos(t)ide analogues only induce temporary hepatitis $B$ e antigen seroconversion in most patients with chronic hepatitis B. Gastroenterology 2010;139:491-498.

26. Werle-Lapostolle B, Bowden S, Locarnini S, Wursthorn K, Petersen
J, Lau G, et al. Persistence of cccDNA during the natural history of chronic hepatitis $B$ and decline during adefovir dipivoxil therapy. Gastroenterology 2004;126:1750-1758.

27. Chan HL, Wong VW, Tse AM, Tse CH, Chim AM, Chan HY, et al. Serum hepatitis $B$ surface antigen quantitation can reflect hepatitis $B$ virus in the liver and predict treatment response. Clin Gastroenterol Hepatol 2007;5:1462-1468.

28. Chan HL, Wong VW, Wong GL, Tse CH, Chan HY, Sung JJ. A longitudinal study on the natural history of serum hepatitis $B$ surface antigen changes in chronic hepatitis B. Hepatology 2010;52:1232-1241.

29. Brunetto MR, Oliveri F, Colombatto P, Moriconi F, Ciccorossi P, Coco $B$, et al. Hepatitis $B$ surface antigen serum levels help to distinguish active from inactive hepatitis $B$ virus genotype $D$ carriers. Gastroenterology 2010;139:483-490.

30. Cai W, Xie Q, An B, Wang H, Zhou X, Zhao G, et al. On-treatment serum $\mathrm{HBsAg}$ level is predictive of sustained off-treatment virologic response to telbivudine in $\mathrm{HBeAg}$-positive chronic hepatitis $\mathrm{B}$ patients. J Clin Virol 2010;48:22-26.

31. Liang Y, Jiang J, Su M, Liu Z, Guo W, Huang X, et al. Predictors of relapse in chronic hepatitis $B$ after discontinuation of anti-viral therapy. Aliment Pharmacol Ther 2011;34:344-352.

32. Chan HL, Wong GL, Chim AM, Chan HY, Chu SH, Wong VW. Prediction of off-treatment response to lamivudine by serum hepatitis $B$ surface antigen quantification in hepatitis B e antigen-negative patients. Antivir Ther 2011;16:1249-1257.

33. Chen $\mathrm{CH}$, Lu SN, Hung CH, Wang JH, Hu TH, Changchien CS, et al. The role of hepatitis $B$ surface antigen quantification in predicting HBsAg loss and HBV relapse after discontinuation of lamivudine treatment. J Hepatol 2014;61:515-522.

34. Chen $\mathrm{CH}$, Hung CH, Hu TH, Wang JH, Lu SN, Su PF, et al. Association Between Level of Hepatitis B Surface Antigen and Relapse After Entecavir Therapy for Chronic Hepatitis B Virus Infection. Clin Gastroenterol Hepatol 2015;13:1984-1992.

35. Chi H, Hansen BE, Yim C, Arends P, Abu-Amara M, van der Eijk AA, et al. Reduced risk of relapse after long-term nucleos(t)ide analogue consolidation therapy for chronic hepatitis B. Aliment Pharmacol Ther 2015;41:867-876.

36. Seto WK, Hui AJ, Wong VW, Wong GL, Liu KS, Lai CL, et al. Treatment cessation of entecavir in Asian patients with hepatitis $B$ e antigen negative chronic hepatitis $B$ : a multicentre prospective study. Gut 2015;64:667-672.

37. Chu CM, Liaw YF. Genotype C hepatitis B virus infection is associated with a higher risk of reactivation of hepatitis $B$ and progression to cirrhosis than genotype B: a longitudinal study of hepatitis B e antigen-positive patients with normal aminotransferase levels at baseline. J Hepatol 2005:43:411-417. 